\title{
02 | Membrana. \\ Límite, conflicto y complicidad en la arquitectura de Livio Vacchini
} Laia Vives Arnella

\begin{abstract}
"Un límite no es aquello en virtud de lo cual algo concluye, sino, aquello a partir de donde algo comienza a ser lo que es, inicia su esencia. Espacio es esencialmente lo que se ha dejado entrar en sus fronteras". 1
\end{abstract}

La arquitectura de Livio Vacchini, arquitecto suizo del Ticino (1933-2007), encuentra su máxima expresión en la frontera que separa el interior del exterior. Este límite es estructura y es detalle; es el punto en el que se filtra y se conduce la luz a través de la geometría de su esqueleto estructural, de su ritmo y de su orden; marca, relaciona y refleja el espacio interior, cualificándolo.

Es en este límite, en el que Livio Vacchini hace evidentes los principios de su arquitectura, tanto para los edificios públicos como para los de uso privado. A través de dos de sus proyectos intentaré explicar cómo se muestra el claro saber hacer de este arquitecto, la vitalidad de su arquitectura y su interpretación tipológica. El proyecto como un límite. El Gimnasio o Sala Multidisciplinar en Losone (Concurso1990-Proyecto y construcción 1995-1997) y la Casa Vacchini en Costa Tenero (Proyecto y construcción 1991-1992).

Para una mejor comprensión del singular carácter de su arquitectura es importante conocer el contexto geográfico y cultural en el que desarrolla toda su trayectoria profesional.

\section{Contexto geográfico y cultural}

Este arquitecto parece responder a la singularidad del cantón del Ticino -cantón de habla italiana situado en la vertiente Sur de los Alpes, en un territorio abierto a Italia, país del que había formado parte hasta el año 1803- dentro de la propia Suiza. Es una zona de fuertes contrastes orográficos, ya que se desarrolla en el encuentro entre los Alpes suizos y los lagos de la Pianura Padana. El resultado es una bella región con una cultura, una lengua y un carácter propios, a la que muchos Ilaman la Suiza Mediterránea.

"El racionalismo constructivo y la atención al contexto se suman como marca distintiva de estos suizos que han sabido reunir el funcionalismo germánico con el monumentalismo clasicista mediterráneo de la Tendenza." 2

En 1970 Luigi Snozzi agrupa a una serie de importantes arquitectos locales: Aurelio Galfetti, Livio Vacchini, Tita Carloni y Mario Botta, entre ellos. Todos compartían los principios de la planificación urbana promovida principalmente a través de los escritos de Aldo Rossi y Vittorio Gregotti. Este grupo de arquitectos reaccionaron en contra de la ideología funcionalista en la planificación de la ciudad acercándose más a la realidad urbana y a la tradición local, como motor de la innovación, o incluso a la búsqueda del rigor arquitectónico basado en el profundo estudio del carácter de la arquitectura pública versus la arquitectura privada. Entendieron el valor social de la arquitectura y se implicaron con gran entusiasmo en resolver proyectos de carácter público (la arquitectura como un medio para investigar y cambiar la realidad). Esta responsabilidad ética (orden, regla, materia, geometría y racionalidad) y el gran valor
Resumen pág 54 | Bibliografía pág 58

Laia Vives, Arquitecta (Barcelona 1973) por la Escuela de Arquitectura del Vallès, Barcelona (ETSAV) en 1999; ha sido asistente de profesor de Robert Brufau desde 1995-1998 en la Escuela Estructural de Arquitectura del Vallès, Barcelona (ETSAV). Desde 2004 es profesora de Proyectos en la Escuela de Arquitectura "La Salle" de Barcelona. Posee un Máster en Proyectos Arquitectónicos de la Escuela de Arquitectura de Barcelona (ETSAB) $y$ actualmente está completando un doctorado Phd en el MPIA Master Proyecto Integrado de Arquitectura en la Escuela de Arquitectura "La Salle".

\section{Palabras clave}

Limite, estructura, luz, detalle constructivo, orden, sistema trilite, público, privado

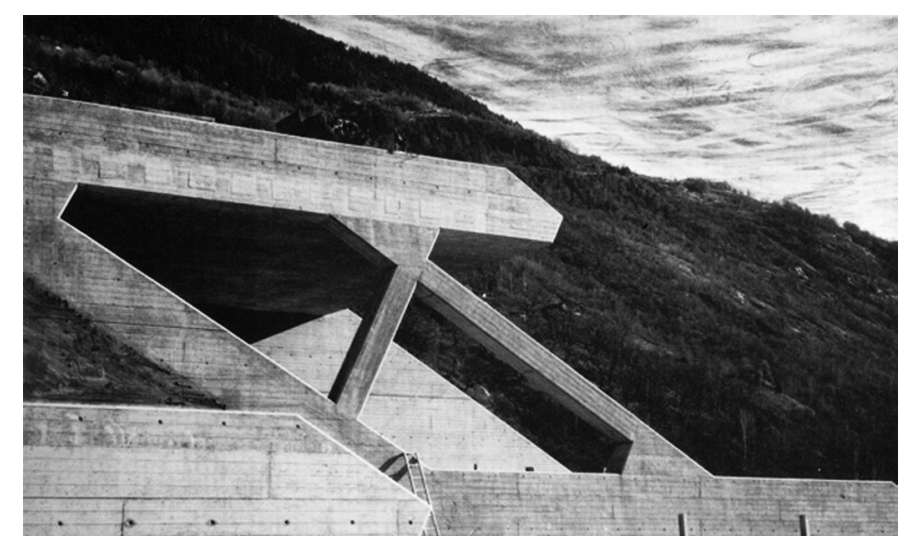


1 HEIDEGGER, Martin; Construir, habitar, pensar, Gustavo Gili, Barcelona, 2008.

2 GILI GALFETTI, Gustau; "Un viaje de ida y vuelta", DPA n ${ }^{\circ} 23$, junio 2007, p. 12. (Monografía sobre Livio Vacchini).

${ }^{3}$ Edificio no orientado. No debe tener distinción en sus cuatro fachadas, todas han de ser iguales, no debe apostar por una direccionalidad.
[1] Fotografía de la autopista A9. Portal de acceso a la galleria en el Ceneri. Foto extraid del documento, "Disegnare linee nel paesaggio, Autostrada N2 Chiassa-San Gottard". (c) Carloni Tita, para la exposición Rino Tami. 50 anni di arcchitettura, Electra, 1984

Fecha: Internet el 11 de diciembre de 2013.

[2] Planta del Gimnasio en Losone. Livio Vacchini. Redibujada por la autora.

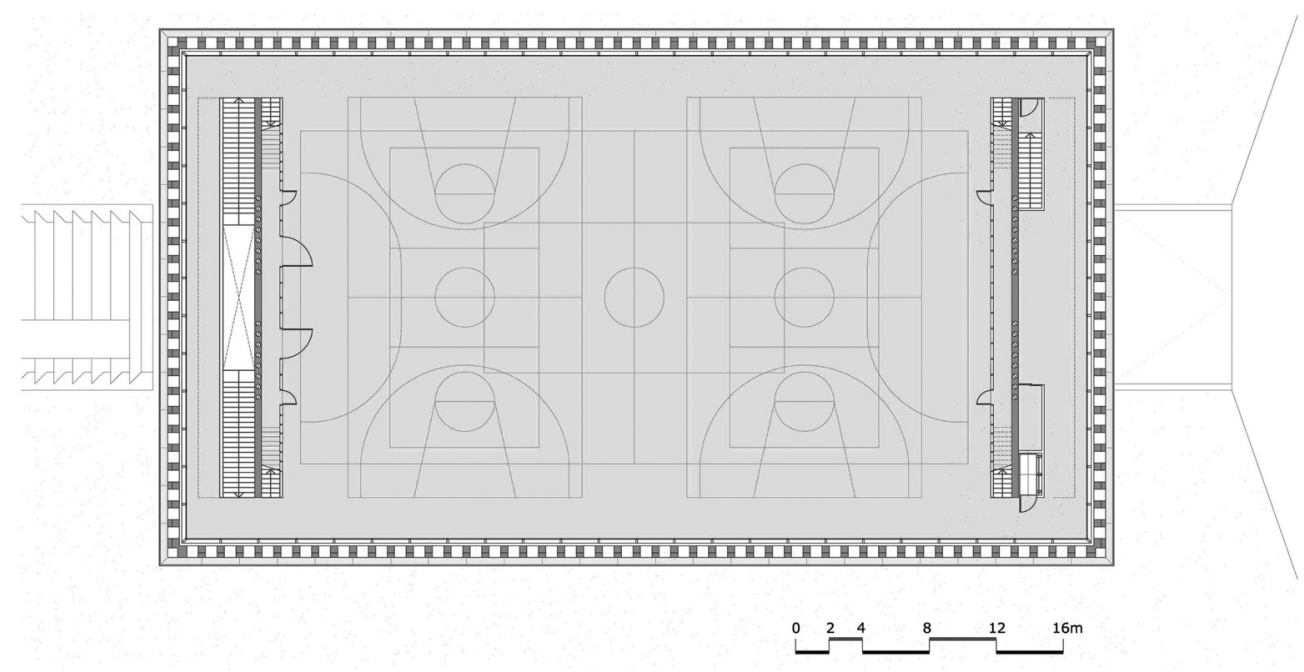

patrimonial de su territorio y de su legado histórico, son los fundamentos para la rica dieta arquitectónica del Ticino.

Este particular espíritu y personalidad se refleja en el modo de entender su arquitectura y su territorio. La autopista que une Italia con el Ticino (Autopista $A 9$ dei Laghi) es un buen ejemplo de los ideales de los arquitectos ticineses: su voluntad de construir el paisaje, sin camuflarse artificiosamente en él; la unidad de material y de geometría para aproximarse con rigor, no exento de sensibilidad, a las características del lugar. [1]

El arquitecto Livio Vacchini se aleja de cualquier contingencia y concentra su pensamiento en resolver y potenciar la artificialidad en su arquitectura, reduciendo el lenguaje arquitectónico a sus elementos principales. Se abstrae de cualquier juego, del lugar o el programa funcional. En su arquitectura cada elemento forma parte del todo, nada sobra.

\section{Edificio público. Gimnasio o sala multidisciplinar en Losone}

Es un edificio situado en un entorno rural próximo a Locarno. Inicialmente el programa demandaba la construcción de una sala con tres campos de juego únicamente para la actividad militar, pero Livio Vacchini, visto el amplio espacio de disposición para realizar el proyecto, convenció al promotor de que sería mejor realizar un proyecto de carácter civil, con el doble uso, un polideportivo de uso público y privado (militares). Un elemento ordenador del contexto urbano y punto de referimiento del territorio.

Para el arquitecto Ticinés un edificio público debe tener la capacidad de ordenar el entorno, "no se orienta" 3 y debe ser un edificio equitativo e igualitario. Livio proyecta una gran sala diáfana, liberada de contingencias funcionales y abierta por sus cuatro fachadas, llevando la estructura a la periferia, como si de una plaza cubierta se tratase. [2]

A primera vista este edificio no revela su uso, aparece como un bloque imponente apoyado sobre un suave terraplén tapizado, una modificación de la corteza terrestre que pone en escena el edificio. La radical solución estructural para disponer de un gran espacio interior, alejado de la contaminación funcional, es un reto constante en la obra del arquitecto; solía decir que la arquitectura empieza cuando termina la función.

El orden es lo que nos distingue de la naturaleza, la arquitectura es artificio, orden, repetición, ritmo, sintaxis de espacios horizontales y/o verticales, en definitiva un lenguaje arquitectónico claro y explícito. [3]

En Losone, un orden único gira en todas direcciones, es como una medusa, "columnas" que descansan en el suelo, se levantan y terminan abriéndose hacia el cielo con un ligero estrechamiento en la parte superior. La secuencia de pilares de hormigón que recorren la fachada y se encuentran en la esquina, reforzándola, y en la que ninguna dirección prevalece sobre la otra. El resultado final es una pieza monolítica que marca la doble direccionalidad de la estructura. [4]

La cubierta reposa sobre los pilares. Este techo está desprovisto de arquitrabes y funciona como una losa bidireccional. La proximidad de las columnas que la sostienen es tal que el sistema portante vertical se comporta como un muro; un muro perimetral de hormigón al que se 

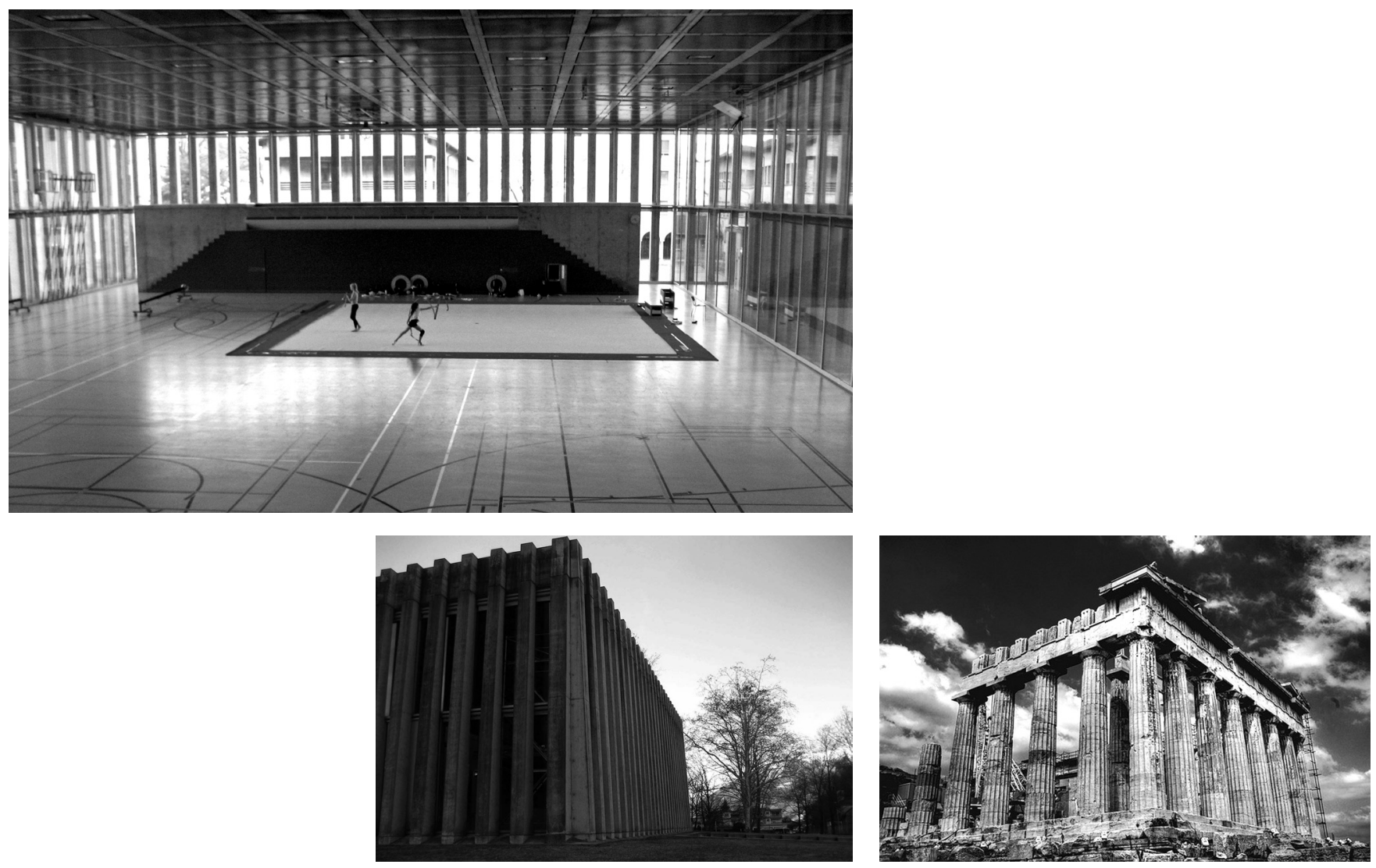

[3] Gimnasio en Losone. En la imagen queda patente el orden, repetición, ritmo, sintaxis de espacios horizontales $\mathrm{y} / \mathrm{o}$ verticales, un lenguaje arquitectónico claro y explícito. Locarno, febrero de 2012. (c) Laia Vives.

[4] Esquina Gimnasio en Losone. Locarno, febrero de 2012. (c) Laia Vives.

[5] Partenón de Atenas. Foto realizada por Zé Valdi (libre de derechos de autor)

Fecha: Internet el 6 de diciembre de 2013.
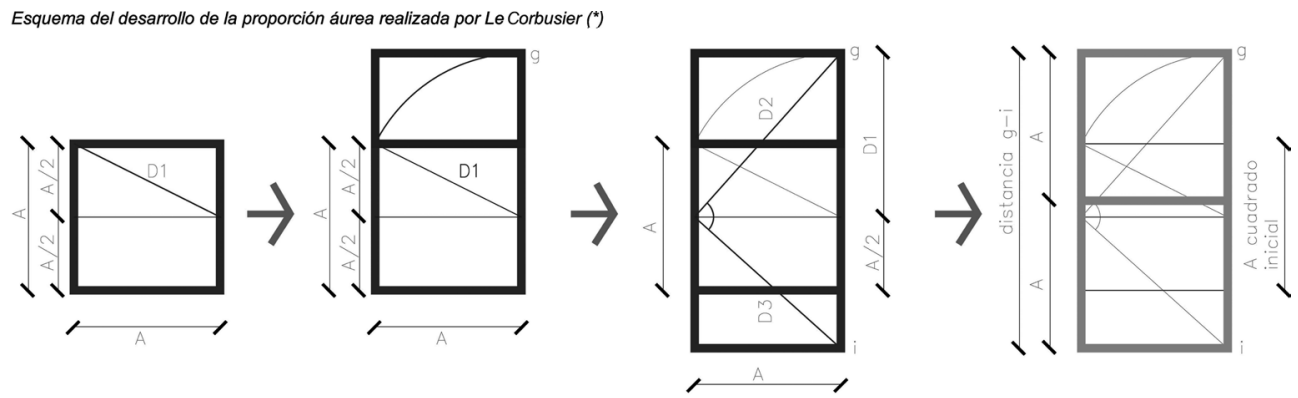

[6] Desarrollo proporción áurea por Le Corbusier. Redibujado por la autora.

[7] Estudio de las proporciones del elemento primario y vacios del Gimnasio. Redibujado por la autora.

[8] Alzado-sección interior del Gimnasio en Losone, carpinteria proporcionada y ajustada a la estructura. Redibujado por la autora.

[9] Sección transversal del Gimnasio en Losone. Encuentro con el terreno y cierre con el cielo. Redibujada por la autora.

Un cuadrado. Diagonal del punto medio a un vértice del cuadrado su sección áurea se obtiene al abatir la diagonal del punto medio del cuadrado ángulo recto del segmento al eje del cuadrado, obteniendo el punto $I$

División en dos partes iguales de la distancia g-i, donde resultan dos cuadrados contiguos iguales al inicial
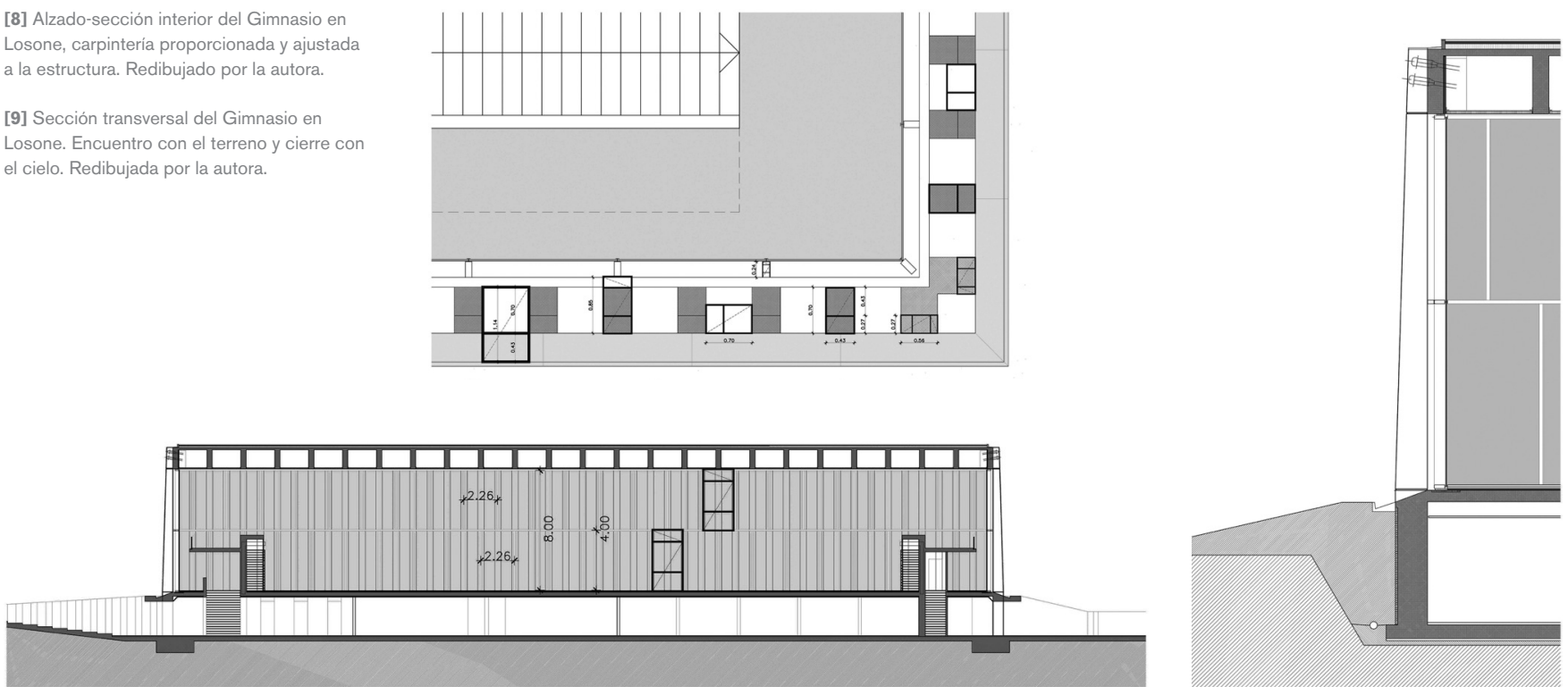
${ }^{4}$ Modulor de Le Corbusier. Un orden arquitectónico capaz de ordenar el cosmos para poder ser habitado y en el que cada pieza tiene la adecuada proporción en sí misma y en el conjunto.

${ }^{5}$ La luz que domina, la luz que construye. La imagen exterior se debe a una acción directa de la luz solar, sin mediación humana, la posición del sol en las distintas horas del día y su intensidad es la única variación natural que percibimos. Dan una sombra de calidad, la sombra que se proyecta sobre el propio material.

${ }^{6}$ La luz que es dominada. El arquitecto tiene la posibilidad de moldear la luz a su capricho. La luz depende de la forma y posición de los orificios por los que penetra. Y a su vez, el espacio que percibimos es consecuencia directa de esta iluminación natural. le practican las máximas aberturas verticales que permite la estática. Sus fachadas se entienden por igual en todas direcciones, los muros que las conforman son inseparables de la cubierta que sostienen. Recuerda a un dolmen; piedras que soportan piedras.

Cada elemento primario (en este caso el pilar de hormigón) tiene una forma ideal dentro de un conjunto mayor, la repetición ordenada de la pieza le da un carácter monumental desde el exterior. Nada es trivial, todo es premeditado. Como en el Partenón, a partir de una regla básica (el diámetro de la columna) se determinan una serie de proporciones que establecen una relación armónica del conjunto. [5]

En el Gimnasio, el tamaño y posición de estas aberturas en los muros asegura una completa permeabilidad de la luz en el interior de la sala, a pesar de su aparente carácter pétreo y monumental desde el exterior.

A partir de una regla básica, la proporción del pilar, se determinan una serie de proporciones que establecen una relación armónica del conjunto, todo el cerramiento está diseñado en base al Modulor ${ }^{4}$. En la Figura 7 se puede observar este juego de relaciones geométricas: cómo la dimensión del hueco es proporcionada a la del pilar. O cómo la proporción del basamento también nos da una pauta de orden y ritmo de las aberturas. $\mathrm{O}$ cómo el solape de la esquina viene también determinado por este juego de proporciones. Nada es trivial. [6, 7]

Desde el exterior la sombra proyectada en las mismas columnas de hormigón roba espacio al vacío que hay entre ellas y la percepción del edificio es la de un monolito ritmado por sombras profundas y sutiles. Es un juego de luz y su ausencia, es una relación permanente de espacio-tiempo que transforma el muro en un elemento compacto y monumental: "la luz dominante." ${ }^{5}$

Por el contrario, en el interior del pabellón "la luz es dominada" 6 , una secuencia de aberturas que van de suelo a techo por sus cuatro fachadas. Luz y sombra en ritmo constante a intervalos idénticos que penetran y se reflejan en el suelo ampliándose y entremezclándose, perdiendo así la sensación de opacidad, producen un efecto de un espacio permeable y abierto hacia el exterior.

En la arquitectura de Livio Vacchini, el doble juego de la opacidad exterior y la transparencia del paisaje desde el interior es una constante.

El cerramiento interior de cristal se ajusta al ritmo de las columnas, se oculta al exterior, y solo una línea a media altura señala el despiece horizontal. Este "horizonte" basado en el 2,26 m del Modulor de Le Corbusier le otorga a la sala la escala humana; es la referencia y la defensa ante un espacio abstracto y alejado del hombre. [8]

Este ajuste cuidadoso del despiece contribuye a la transparencia y desmaterialización del cerramiento y la percepción de una cubierta que parece flotar sobre la pista. Como si de una plaza cubierta se tratase.

Los pilares que forman las fachadas y soportan la cubierta, de 1,40 m de grosor, no tienen un tope superior, van hacia el cielo. Mientras, en su parte inferior, descansan sobre un apoyo horizontal ligeramente inclinado (para recoger las aguas) pero creando una incisión (una sombra) en la tierra. De este modo, consigue marcar el nivel del suelo del interior $y$, al mismo tiempo, que los pilares no parezcan emerger del suelo, sino nacer de una base, haciendo evidente su punto de contacto. [9]

Livio Vacchini siempre busca un juego de relaciones geométricas y visuales en sus proyectos. Un ejemplo de ello se puede observar en la zona de acceso del público, en la que el inicio de la rampa que te adentra en el edificio se encuentra 1,40 m por debajo de la cota de la pista, por lo que la visual del visitante queda a la altura de la cota interior del pavimento, dando así la "pista" de su uso interior. Esta dimensión de 1,40 m se repite en el grosor de la estructura de cubierta, presente desde del exterior; todo tiene que estar proporcionado y relacionado. [10]

Todas las fachadas son iguales, no hay puertas, ni ventanas, solo estructura y vacío. ¿Cómo crear un acceso a su interior sin debilitar su aspecto monolítico exterior y de luz ritmada en el interior? Livio Vacchini soluciona el problema con un artificio muy elegante; su ajustada disposición en el solar le permite acceder al pabellón por debajo de la cota del terreno y por sus dos lados más cortos creando un acceso para el público por un lado y, por el otro, para los militares, cliente final de este proyecto. 

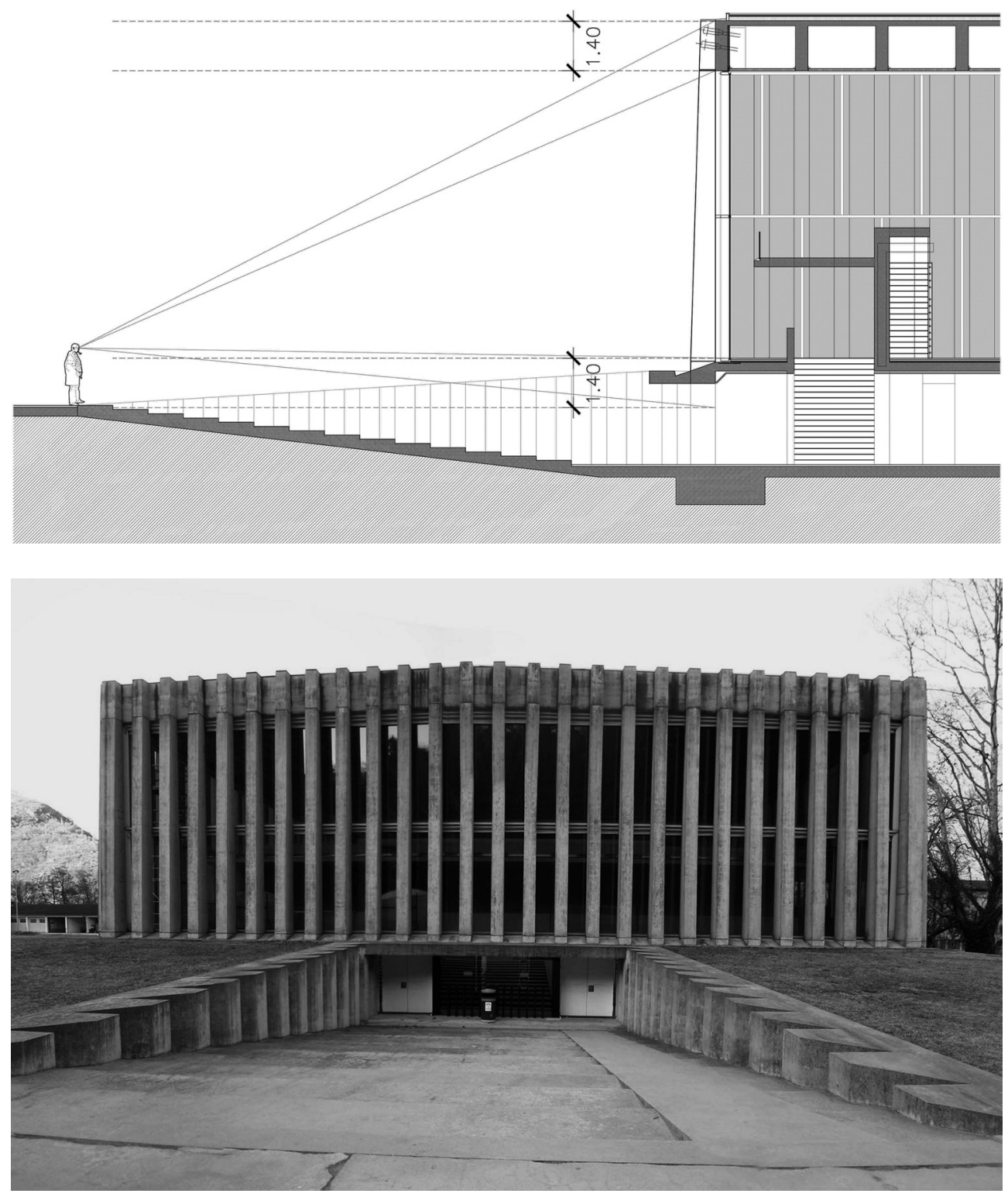

Crea una promenade con una sutil rampa-escalera que te conduce desde la calle al plano inferior del pabellón. En el camino reproduce las proporciones de la estructura del edificio en los muros de contención laterales de la rampa, hendiduras en los muros en las que la luz y la sombra te acompañan ritmadamente hasta el corazón del edificio. [11]

\section{Edificio privado. Casa Vacchini en Costa Tenero}

Después de este recorrido por el Gimnasio en Losone, nos adentramos en un proyecto realizado en el mismo período, la Casa Vacchini en Costa Tenero. Su segunda residencia familiar, que significó un punto de inflexión en su recorrido profesional. Un proyecto en que tensa al máximo el sistema estructural y en el que define con claridad el plano del hombre invirtiendo la relación interior-exterior.

La disposición y configuración de las casas en la zona de Costa Tenero encastadas en la montaña con la fachada mayor paralela a las curvas de nivel, se contrapone a la casa Vacchini. Un paralelepípedo con una proporción en planta 1:2 aproximadamente y una disposición perpendicular a la máxima pendiente de la montaña que pone en jaque el sistema de relaciones artificio-naturaleza de la zona.

Establece un diálogo directo con el contexto geográfico, es una relación de contrapunto entre el Orden y Pureza del objeto y la acentuada orografía de los Alpes. Es una casa extrovertida, que se asoma al paisaje, pero a la vez introvertida, se autoprotege del peligro exterior. Es una arquitectura directa que utiliza la naturaleza para mostrar en plenitud la bondad del artificio.

“... La arquitectura de la casa en la que nos encontramos hoy en día es introvertida. Las casas que he realizado hasta día de hoy son extrovertidas, son casas que atacan y que se comen las 
${ }^{7}$ Entrevista Jean Gerard Giola a Livio Vacchini. "No existen los detalles",

Revista Quaderns d'Arquitectura i Urbanisme $\mathrm{n}^{\circ}$ 167-168, pp. 104-125.

${ }^{8}$ Tipología orientada. Dirigida hacia algo que debe tender a una disposición longitudinal, con un diálogo distinto en cada una de sus direcciones. Un edificio con un delante y un detrás; con un espacio interior siempre dual, un espacio servido y uno servidor.

${ }^{9}$ Sistema Trilite. Fundamento que se encuentra en el lenguaje clásico y se compone de tres partes: el mundo en el que la arquitectura se apoya en el suelo, el mundo en que la arquitectura se alza (donde aparecen términos como orden, ritmo y simetría) y el mundo en el que se cierra al cielo creando así el espacio para cubrir y proteger al hombre, finalidad de toda arquitectura.
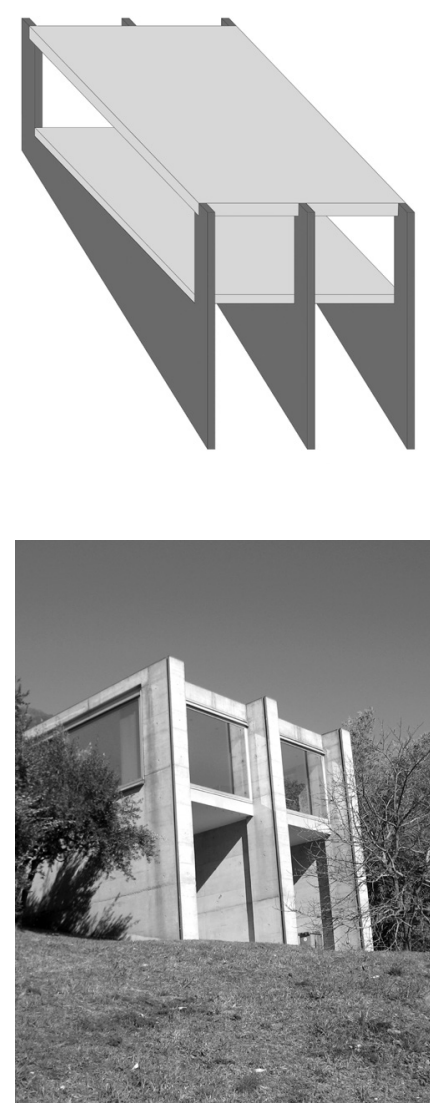

casas que hay alrededor... Es necesario hacer casas hermosas, no hay que hacer nada más que ejecutar obras de calidad. Esta es mi opinión". Livio Vacchini. ${ }^{7}$

Según Livio Vacchini, un edificio privado es una "tipología orientada" 8 , en la que la luz es la que confiere la categoría superior al espacio vital y, en consecuencia, no debe ser una cuestión menor cómo la conducimos y baña el interior.

El plano del hombre se apoya en tres muros de hormigón que se adaptan a la topografía y que resuelven la estructura. En él, los tres muros se abren al máximo hasta reducirse a tres machones en las caras anterior y posterior del rectángulo, estos soportan la cubierta, que se resuelve con una gran viga-losa de hormigón postesada, y permiten introducir la luz y la vida en el interior de la vivienda. [12]

El esqueleto estructural se muestra en el exterior con toda su potencia, dignificando la estructura, alejándola de la función. Estructura, concepto y composición formando una unidad de lenguaje arquitectónico.

La casa es un solo espacio dividido en dos tal como se muestra desde la concepción de la estructura. Un módulo central de servicios y cocina organiza la planta de manera centrípeta, abriendo al paisaje el espacio interior a través de grandes ventanales continuos. [13]

La estructura, como elemento primario que forma la envolvente de la casa, se muestra con toda su potencia y consigue con un solo gesto unificar el "sistema trilite" 9 ; con un ritmo diverso en la envolvente según la orientación: grandes luces sin interrupciones en las fachadas laterales y la expresión bi-dual del espacio en las fachadas principal y posterior. Forma una unidad de lenguaje arquitectónico.

El protagonismo se traslada a las fachadas laterales que llenan de luz y facilitan la ventilación cruzada en el interior habitable estableciendo un diálogo directo con el contexto geográfico. [14] Cada fachada esconde "emociones" distintas, visuales dispares. Las fachadas laterales, abiertas de suelo a techo y sin estructura, se relacionan con las pendientes y los árboles, hay una percepción continua del exterior, la arquitectura "desaparece" y se acerca a la naturaleza. La fachada frontal, por lo contrario, se encara al lago y los pilares se convierten en el marco, la panorámica ya no te pertenece por distancia, simplemente se observa. Mientras que la fachada posterior de acceso es completamente opaca, solo un voladizo de hormigón reflejado en el pavimento por un gran peldaño para alcanzar el plano noble, señala el acceso, el umbral de la casa, el límite con el espacio privado. [15]
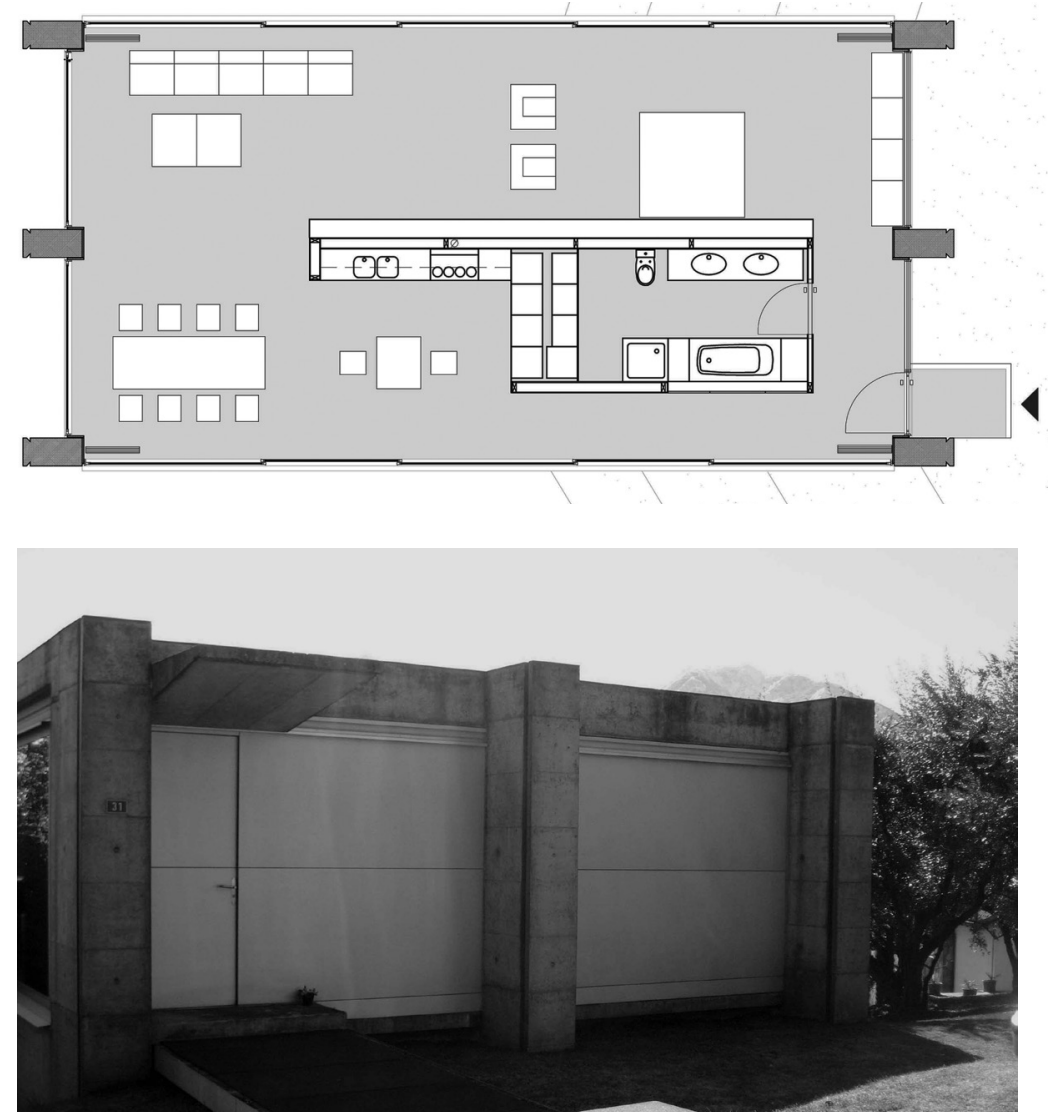
Cada detalle constructivo de la casa forma parte del todo y no se puede sacar ni añadir nada. Livio Vacchini busca la repetición de elementos primarios con la voluntad de reducir métodos y elementos constructivos haciendo una arquitectura unitaria, volumétrica y elemental.

La carpintería exterior, que va de suelo a techo en toda la vivienda, se sitúa en el mismo plano que la estructura en las fachadas longitudinales, una hendidura en el marco de la ventana enfatiza con su sombra el hueco que crea la estructura, al mismo tiempo que define el escupidero de la carpintería. [16] La proporción áurea del despiece de la carpintería no es igual en todas ellas, su composición está formada por unos módulos de proporción áurea (2,50 m x 3,45 m, A/ $\mathrm{A}+\mathrm{C})$ que son fijos y un módulo cuadrado $(2,50 \mathrm{~m} \times 2,50 \mathrm{~m}, \mathrm{~A} / \mathrm{A})$ que será la corredera. [17] En la fachada frontal las carpinterías son fijas y tienen la misma dimensión y proporción que en las fachadas laterales, pero en este caso tanto el forjado como la carpintería disponen su límite con el pilar con un solape de $35 \mathrm{~cm}$ de la cara interior de este. [18]

El efecto metalizado del vidrio refleja los olivos y da privacidad a la casa, mientras que, desde el interior, el vidrio se oscurece pero permite la visual de todo el paisaje, en definitiva, ves sin ser visto. Las ventanas y la luz natural crean un juego de transparencias y reflejos con el hormigón de la estructura que unifica abertura y muro.

En el tratamiento de los pilares de hormigón también se crea una dualidad entre el interior y el exterior de la casa. Mientras en el exterior el hormigón tiene un carácter monolítico, es una forma unitaria e indivisible; en el interior, por razones constructivas del aislamiento térmico, los pilares se revisten con un panel de DM creando un juego de colores; las caras laterales del pilar se pintan de blanco para dar cierta continuidad visual con el pilar por el exterior, y en la cara frontal el DM se laca de color negro.
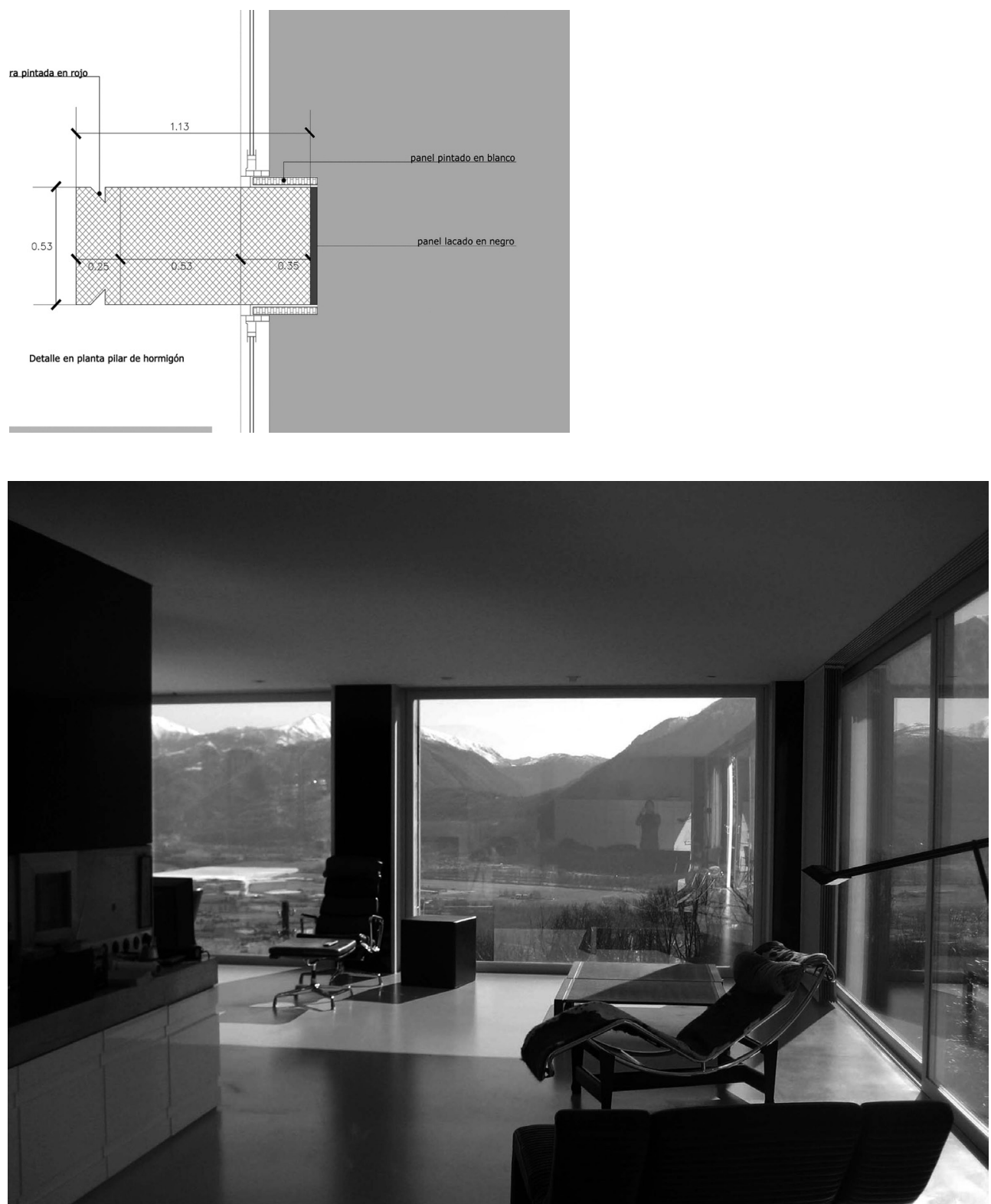

[16] Detalle pilar fachada frontal. Casa Vacchini en Costa Tenero. Redibujado por la autora.

[17] Vista desde la sala hacia el exterior, fachada frontal al valle, casa Vacchini en Costa Tenero. Locarno, febrero de 2012. (c) Laia Vives.

[18] Sección fachada longitudinal, creando una hendidura, una sombra en la parte superior. Redibujado por la autora.

[19] Sección fachada acceso, plano del hombre levantado respecto terreno, creando una hendidura, una sombra. Redibujado por la autora.

[20] Vista de la fachada de acceso, plano del hombre levantado respecto al terreno, creando una hendidura, una sombra. Foto realizada por la autora en un viaje a Locarno en febrero de 2012.

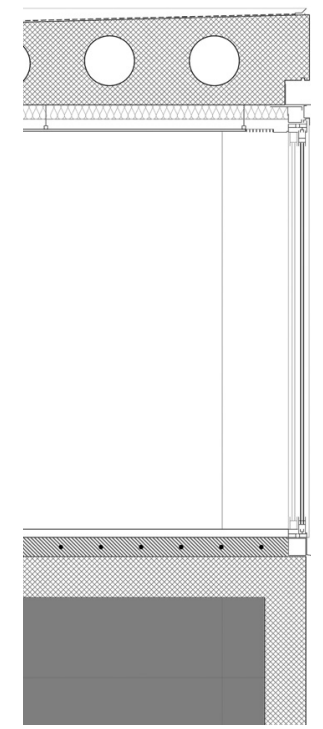



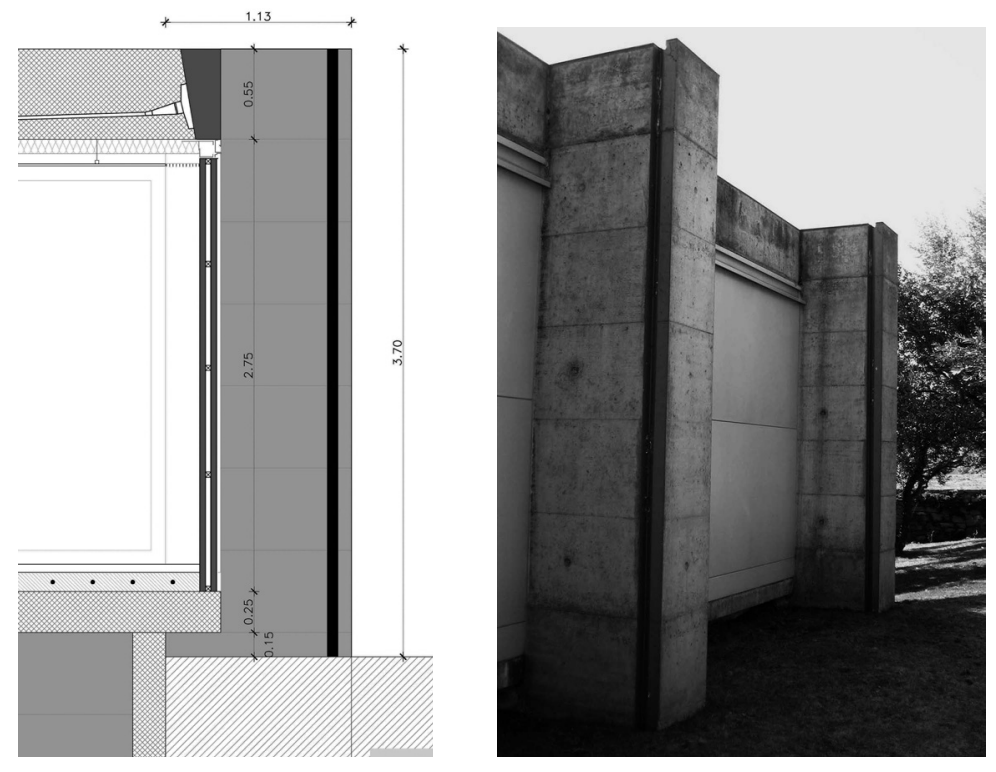

La singularidad del pensamiento de Livio Vacchini respecto de la transición entre el espacio público y el privado, se manifiesta en las hendiduras pintadas de color rojo, en toda la longitud de ambos lados de los machones de hormigón exteriores. Esta incisión pone al visitante en tensión, para que entienda que está en el umbral de la casa, en el límite entre el exterior y el mundo interior del edificio (como en el Gimnasio en Losone, con la rampa y la repetición ritmada de la proporción del elemento estructural).

Esta hendidura roja también acentúa que es la estructura de hormigón la que se levanta del suelo, se alza y se cierra en el cielo; enfatiza el elemento vertical continuo y el que se interrumpe es el plano horizontal, manda la columna. El plano del hombre queda levantado del plano de la montaña lo suficiente como para crear una sombra y dejar claro que está sustentado por los muros de hormigón. [19, 20]

Pero hay una reflexión más sobre por qué Livio Vacchini hace esta hendidura. La estructura está aparentemente sobredimensionada para sustentar una cubierta relativamente sencilla, por lo que se entiende que quiere dejar claro que la estructura de la casa está formada por muros portantes y no por pilares como puede parecer a primera vista. Un muro tiene una direccionalidad clara, no gira, al contrario que un pilar, que es exento y por tanto gira en todas sus caras; Livio Vacchini refuerza esta idea con estas hendiduras pintadas, consiguiendo así separar la esquina, crear una "tapa", para dejar claro que la estructura no gira.

“...la hendidura crea una sombra sobre el propio material y así consigue separarse!..." Eloisa Vacchini. ${ }^{10}$

10 Entrevista inédita de Laia Vives Arnella a Eloisa Vacchini. "Teoría de los colores", transcrita al castellano para la tesis doctoral de Livio Vacchini. Obra y Pensamiento.
Utiliza un único material para los muros y la losa, el hormigón. Esto le permite dar un carácter unitario a los dos edificios de estudio. En la vivienda, lo "ornamenta exteriormente" con el despiece del encofrado, creando unas leves hendiduras, como si de un revestimiento de piedra se tratase, dándole la escala humana al objeto.

A través de estos dos proyectos, se ha explicado cómo Livio Vacchini reconstruye el grosor entre el dentro y el fuera de un edificio. Cómo en este límite, en el confín entre el interior y el exterior, reside la fuerza de su arquitectura; es estructura, es detalle y filtro de luz.

Es el punto en el que se engloban todos sus principios (determina si el edificio es público o privado), marca las reglas de juego (pone orden, ritmo y proporción a la estructura) y a través de unos instrumentos (material, detalle constructivo y técnica) construye.

Reconstruye el grosor entre el dentro y el fuera; el filtro es construcción. Exteriormente la luz hace presente el carácter sólido y monumental del edificio, mientras que desde su interior las paredes están presentes pero casi sin materia, y todo debido a la luz. Esta entra a través del filtro, pero no de la misma manera por las cuatro fachadas, en el mismo momento, siempre hay luz y sombra que se filtra a través del esqueleto del edificio y esto es lo que modela el espacio del hombre. Construye el espacio interior. Hace arquitectura. 